\title{
Dyspnea in lung cancer patients: a systematic review
}

\author{
This article was published in the following Dove Press journal: \\ Lung Cancer:Targets and Therapy \\ 22 November 2010 \\ Number of times this article has been viewed
}

\section{Ganesan Kathiresan' \\ Reynold F Clement ${ }^{2}$ \\ Meera T Sankaranarayanan ${ }^{2}$ \\ 'Department of Physiotherapy, School of Allied Health, Masterskill University College, Sabah, Malaysia; ${ }^{2}$ Department of Biological Sciences, Essex University, Colchester, UK}

Correspondence: Ganesan Kathiresan Masterskill University College, Likas, Kotakinbalu, Sabah, Malaysia Tel +l 60176033025

Email gans_therapist@yahoo.co.in; kathiresan@masterskill.edu.my

\begin{abstract}
Dyspnea is a common and distressing symptom experienced by $19 \%-51 \%$ of patients with advanced cancer. Higher incidences are reported in patients approaching end of life. While the prevalence of dyspnea has been reported to be as frequent as pain in people with lung cancer, less attention has been paid to the distress associated with dyspnea. This review of the literature was undertaken to investigate how dyspnea has been assessed and whether breathlessness in people with lung cancer is distressing. Using a predetermined search strategy and inclusion criteria, 31 primary studies were identified and included in this review. Different outcome measures were used to assess the experience of dyspnea, with domains including intensity, distress, quality of life, qualitative sensation, and prevalence. Overall, the studies report a high prevalence of dyspnea in lung cancer patients, with subjects experiencing a moderate level of dyspnea intensity and interference with activities of daily living. Distress associated with breathing appears to be variable, with some studies reporting dyspnea to be the most distressing sensation, and others reporting lower levels of distress. However, taking into account the prevalence, intensity, and distress of dyspnea, the general consensus appears to be that the experience of dyspnea in people with lung cancer is common, with varying degrees of intensity, but involves considerable unpleasantness. Thus, if dyspnea and pain are both distressing sensations for people with lung cancer, this has potential implications for both clinical and academic areas with regards to both management strategies and further research.
\end{abstract}

Keywords: breathlessness, distress, neoplasm, scale, fatigue

\section{Introduction}

Lung cancer, the most common cause of cancer-related death in men and women, is responsible for 1.3 million deaths worldwide annually. ${ }^{1}$ Mortality from lung cancer remains very high worldwide. Lung cancer is the leading cause of cancer death in the United States, with an estimated 565,650 people dying from lung cancers in 2008. ${ }^{2}$ People with lung cancer experience symptoms which vary between individuals, resulting in a range of symptoms which people might find distressing. ${ }^{3}$ There are several common signs and symptoms associated with lung cancer, which can be classified as a result of the primary tumor, intrathoracic spread, distant metastases, paraneoplastic syndromes, or nonspecific symptoms. ${ }^{3}$ The most common signs and symptoms relating to a primary lung tumor, and therefore corresponding to early stage disease, are nonspecific symptoms such as weight loss or fatigue. Cough, dyspnea (distress with breathing or breathing discomfort), hemoptysis (coughing up blood), and chest discomfort are also common in the initial stages of lung cancer. ${ }^{3}$ 
Pain and dyspnea have been reported to be common distressing symptoms in people with cancer. Beckles et al report that while $6 \%-25 \%$ of people with lung cancer will experience bone pain and $20 \%-49 \%$ will experience chest pain, somewhere between $3 \%$ and $60 \%$ will experience dyspnea. ${ }^{3}$ While the incidence of dyspnea in people with lung cancer is reported to be at least as frequent as pain, its presence is underappreciated and potentially not analyzed or investigated to the same extent. ${ }^{4}$ For example, a preliminary search of the Scopus database reveals almost twice as much literature addressing pain and pain management in people with lung cancer, compared with that of dyspnea. The purpose of this paper is to review primary studies of people with lung cancer in order to answer two specific questions:

1. Which outcome measures have been used to assess dyspnea?

2. What evidence is there that breathlessness is distressing?

\section{Search strategy}

A systematic search process was undertaken to identify peerreviewed publications specifically investigating the sensation of breathlessness in people with lung cancer. When developing the review question, the $\mathrm{PICO}^{5}$ (population, interventions, comparisons, and outcomes) structure was used. The population of interest was adults with lung cancer, of any type or stage. Studies were limited to observation or epidemiological studies. As the intent of the systematic review was not to explore the evidence for management strategies for breathlessness, no intervention or comparator was specified for this question. The outcome of interest was data on the sensation of dyspnea or breathlessness. Three groups of search terms were identified. The first group included lung cancer and lung neoplasms; the second, dyspnea and breathlessness; and the third, distress, perception, and sensation. Each term within a

Table I Retrieved and retained citations from each database

\begin{tabular}{llll}
\hline Database & $\begin{array}{l}\text { Date of } \\
\text { search }\end{array}$ & $\begin{array}{l}\text { Retrieved } \\
\text { citations }\end{array}$ & $\begin{array}{l}\text { Retained } \\
\text { citations }\end{array}$ \\
\hline MEDLINE & $26 / 02 / 2009$ & 339 & 2 \\
Embase & $26 / 02 / 2009$ & 418 & 8 \\
Cochrane & $26 / 02 / 2009$ & 137 & 0 \\
Library & & & \\
CINAHL & $28 / 02 / 2009$ & 186 & 13 \\
PsycINFO & $28 / 02 / 2009$ & 174 & 2 \\
Scopus & $2 / 3 / 2009$ & 391 & 6 \\
\hline
\end{tabular}

group was separated by "or", and each group was separated by "and". The database search was undertaken between late February and early March 2009. The Ovid MEDLINE, Embase, Cochrane Library, CINAHL, PsycINFO, and Scopus databases were searched using the default settings except in Ovid, where "advanced search" was used. Table 1 presents the citations retrieved using the search strategy, and those which were retained from each database.

During the first wave of the search, citations were retained if they met the following five criteria:

1. The abstract or title refers to distress/perception/sensation of dyspnea/breathlessness or symptoms, rather than psychological distress.

2. It does not refer to any drugs for the treatment of breathlessness/dyspnea.

3. Subjects include those with lung cancer.

4. Language of the publication is English.

5. The publication is a peer-reviewed journal article (not gray literature).

The search identified 143 articles where the title met the inclusion criteria. When information in the abstract for each citation was reviewed, 36 citations were excluded as they did not meet the inclusion criteria. Full-text versions of citations were retrieved for the remaining 107 articles meeting the inclusion criteria or where abstracts were ambiguous and could not be confidently excluded from the review. Upon retrieval of the full versions, articles were included within the systematic review if they met the following four criteria (second wave of review):

1. It meets the above five criteria on review of the full-text article.

2. It is not a study investigating an intervention for the management of breathlessness, except for cohort studies which include an intervention as part of the normal treatment (eg, surgery, chemotherapy, or radiotherapy) and were not compared with a control group (ie, not explicitly an intervention study).

3. It reports original primary data (continuous ratio, categorical, nominal scales, or text) on the presence of dyspnea (intensity/qualitative sensation/severity/associated distress).

4. Data specific to people with lung cancer are able to be extracted.

Thirty-one articles were retained that satisfied the above criteria. Table 2 details each of the studies included in the review in terms of research design, sample size, and stage of cancer. 
Table 2 Characteristics of the articles retained from the second wave of the search strategy

\begin{tabular}{|c|c|c|c|}
\hline Article & Research design & Sample size (n) & Lung cancer stage \\
\hline Tishelman et al $^{6}$ & Longitudinal & 400 & I-IV \\
\hline Broberger et $\mathrm{al}^{7}$ & Longitudinal & 46 & Not reported \\
\hline Henoch et $\mathrm{al}^{8}$ & Longitudinal & 105 & Not reported \\
\hline Hirakawa et al $^{9}$ & Observational & $33(26 \%)$ & Not reported \\
\hline Tanaka et $\mathrm{al}^{10}$ & Observational & 157 & IIIA-IV and recurrent \\
\hline Heedman and Strang'I & Longitudinal & $60(14 \%)$ & Not reported \\
\hline Smith et $\mathrm{al}^{12}$ & Observational & 120 & I-IV \\
\hline Hopwood and Stephens $s^{13}$ & Observational & 819 & Not reported \\
\hline Sarna $^{14}$ & Observational & 69 & Not reported \\
\hline Brown et al ${ }^{15}$ & Longitudinal & 30 & Limited + extensive disease + stage III \\
\hline Lai et $\mathrm{al}^{16}$ & Qualitative descriptive & II & IIIB and IV \\
\hline Broberger et al ${ }^{17}$ & Longitudinal & 85 & Not reported \\
\hline $\mathrm{Oh}^{18}$ & Cross-sectional & 106 & I-IV \\
\hline Kuo and $\mathrm{Ma}^{19}$ & Descriptive correlation & 73 & Majority stage IV, others not reported \\
\hline Tanaka et $\mathrm{al}^{20}$ & Observational & |7| & III, IV, or recurrent stage \\
\hline Tanaka et $\mathrm{al}^{2 !}$ & Observational & I7I & III, IV, or recurrent stage \\
\hline Kurtz et $\mathrm{a}^{22}$ & Longitudinal & 228 & Early and late stage disease \\
\hline Lutz et $\mathrm{al}^{23}$ & Observational & 69 & IV, extensive stage, locally recurrent \\
\hline Tishelman et $\mathrm{al}^{24}$ & Longitudinal & 26 & Not reported \\
\hline Kurtz et $\mathrm{al}^{25}$ & Cross-sectional & 129 & Early and late stage disease \\
\hline O'Driscoll et $\mathrm{al}^{26}$ & Prospective RCT & 52 & Not reported \\
\hline Lobchuk et $\mathrm{al}^{27}$ & Observational & 41 & $\begin{array}{l}\text { Limited and extensive } \\
\text { disease, stages I-IV }\end{array}$ \\
\hline Sarna and Brecht ${ }^{29}$ & Observational & 60 & Advanced stage \\
\hline Sarna ${ }^{28}$ & Observational & 65 & Not reported \\
\hline McCorkle and & Longitudinal & 67 & Not reported \\
\hline \multicolumn{4}{|l|}{ Quint-Benoliel $^{30}$} \\
\hline Chan et $\mathrm{al}^{31}$ & Longitudinal & 27 & Advanced stage \\
\hline Clayson et $\mathrm{al}^{32}$ & Qualitative & 15 & Not reported \\
\hline Tishelman et $\mathrm{al}^{33}$ & Longitudinal & 400 & I-IV \\
\hline Akechi et $\mathrm{al}^{34}$ & Longitudinal & 129 & III-IV \\
\hline Dudgeon et $\mathrm{al}^{35}$ & Observational & $37(4 \%)$ & Not reported \\
\hline Langendijk et $\mathrm{al}^{36}$ & Observational & 262 & I-IV \\
\hline
\end{tabular}

Abbreviation: RCT, randomized controlled trial.

\section{Appraisal of potential bias}

Each article was appraised for potential bias using a fourpoint checklist devised especially for use in this review. The following four key points were identified that could potentially affect the believability of the dyspnea data:

1. Subjects needed to have a definite diagnosis of lung cancer.

2. Reliability and validity needed to be reported or cited for the dyspnea outcome measure.

3. The assessment method needed to be described adequately to permit repeatability.

4. The data needed to represent the lung cancer patients (ie, minimal missing data).

Table 3 presents the results of the appraisal process. A shaded cell indicates the study fulfilled the criterion, whereas an unshaded cell indicates it was unclear from the detail provided in the study as to whether the criterion was satisfied. Nine of the 31 articles satisfied the four criteria. All of the studies met the first criterion of a diagnosis of lung cancer. Twenty-four articles reported the reliability and validity of the instrument used to assess dyspnea, and 17 studies reported a complete or near complete dataset. Large amounts of missing data have the potential to bias the study's results and influence the believability of the data. The least satisfied criterion occurred in the description of the assessment method, with only 16 studies providing sufficient detail to allow for replication. Thus, bias potentially exists for the reliability and validity of assessment tools for dyspnea and for the replicability of the studies. A single study satisfied only one criterion, with the majority of studies satisfying all or most of the criteria. Therefore, confidence can be placed to some extent in the accuracy of the believability of the dyspnea data. 
Table 3 Appraisal of potential bias within studies $(n=3 I)$

\begin{tabular}{|c|c|c|c|c|}
\hline Article & Lung cancer & Tool & Method & Data \\
\hline Tishelman et $\mathrm{al}^{6}$ & $x$ & $x$ & $x$ & $x$ \\
\hline Broberger et $\mathrm{al}^{7}$ & $x$ & $x$ & $x$ & $x$ \\
\hline Henoch et $\mathrm{al}^{8}$ & $x$ & $x$ & $\mathrm{O}$ & $x$ \\
\hline Hirakawa et al ${ }^{9}$ & $x$ & O & O & $x$ \\
\hline Tanaka et al ${ }^{10}$ & $x$ & $x$ & $x$ & $x$ \\
\hline Heedman and Strang" & $x$ & O & $\mathrm{O}$ & $x$ \\
\hline Smith et al ${ }^{12}$ & $x$ & $x$ & $x$ & $\mathrm{O}$ \\
\hline Hopwood and Stephens ${ }^{13}$ & $x$ & O & $\mathrm{O}$ & $x$ \\
\hline Sarna ${ }^{14}$ & $x$ & $x$ & $x$ & $\mathrm{O}$ \\
\hline Brown et al ${ }^{15}$ & $x$ & $x$ & $\mathrm{O}$ & $\mathrm{O}$ \\
\hline Lai et $\mathrm{al}^{16}$ & $x$ & $x$ & $x$ & $x$ \\
\hline Broberger et $\mathrm{al}^{17}$ & $x$ & $x$ & $\mathrm{O}$ & $\mathrm{O}$ \\
\hline $\mathrm{Oh}^{18}$ & $x$ & $x$ & $x$ & $x$ \\
\hline Kuo and $\mathrm{Ma}^{19}$ & $x$ & $x$ & $\mathrm{O}$ & $\mathrm{O}$ \\
\hline Tanaka et a $\left.\right|^{20}$ & $x$ & O & $x$ & $x$ \\
\hline Tanaka et $\mathrm{a}^{2 !}$ & $x$ & $x$ & $x$ & $x$ \\
\hline Kurtz et $\mathrm{al}^{22}$ & $x$ & $x$ & $x$ & $x$ \\
\hline Lutz et $\mathrm{al}^{23}$ & $x$ & $x$ & $\mathrm{O}$ & $\mathrm{O}$ \\
\hline Tishelman et $\mathrm{al}^{24}$ & $x$ & $x$ & $\mathrm{O}$ & $x$ \\
\hline Kurtz et $\mathrm{al}^{25}$ & $x$ & $\mathrm{O}$ & $x$ & $x$ \\
\hline O'Driscoll et $\mathrm{al}^{26}$ & $x$ & $x$ & $\mathrm{O}$ & O \\
\hline Lobchuk et $\mathrm{al}^{27}$ & $x$ & $x$ & $\mathrm{O}$ & $\mathrm{O}$ \\
\hline Sarna and Brecht ${ }^{29}$ & $x$ & $x$ & $\mathrm{O}$ & $\mathrm{O}$ \\
\hline Sarna $^{28}$ & $x$ & $x$ & $x$ & $x$ \\
\hline McCorkle and Quint-Benoliel ${ }^{30}$ & $x$ & $x$ & $x$ & $\mathrm{O}$ \\
\hline Chan et $\mathrm{al}^{31}$ & $x$ & $x$ & $x$ & $x$ \\
\hline Clayson et $\mathrm{al}^{32}$ & $x$ & $\mathrm{O}$ & $x$ & $\mathrm{O}$ \\
\hline Tishelman et $\mathrm{al}^{33}$ & $x$ & $x$ & $x$ & O \\
\hline Akechi et $\mathrm{al}^{34}$ & $x$ & $\mathrm{O}$ & $\mathrm{O}$ & $\mathrm{O}$ \\
\hline Dudgeon et $\mathrm{a}^{35}$ & $x$ & $x$ & O & $x$ \\
\hline Langendijk et $\mathrm{al}^{36}$ & $x$ & $x$ & O & O \\
\hline
\end{tabular}

Abbreviations: $X$, satisfied criterion; $O$, unclear whether criterion satisfied.

\section{Outcome measures for dyspnea}

Eighteen separate outcome measures were used to assess breathlessness in the 31 studies (Table 4). Studies using different types of questionnaires and interviews were grouped under the collective terms of "questionnaire" or "interview". Several composite outcome measures included a number of different discrete outcome measures. For example the Edmonton Symptom Assessment Scale (ESAS) consists of nine separate visual analog scales (VAS). Table 4 presents the outcome measures used to assess the sensation of breathlessness.

\section{Domains of dyspnea assessment}

The following section collates and reports the degree of distress with the sensation of breathlessness in people with lung cancer. The 18 dyspnea outcome measures were grouped into similar domains. Table 5 presents the five domains for dyspnea assessment, and the outcome measures which fall under each category. Several outcome measures are listed in two or more domains as they satisfy multiple criteria. However, outcomes were also listed in several or alternative columns to which they were originally intended. For example, the VAS and the Verbal Rating Scale for dyspnea (VRS) have the ability to measure the intensity of dyspnea; however, as the intensity was not reported in the study, data were only able to be extracted on the presence of dyspnea and thus were classified under an alternative heading for which they were originally designed. ${ }^{35}$ Whether the data obtained from studies using a longitudinal design are based on baseline measures or averaged over several time periods is also reported.

\section{Symptom intensity VASs}

Four studies assessed resting dyspnea using a VAS anchored with "no dyspnea" to "maximum dyspnea". 11,15,16,31 Overall, these four 


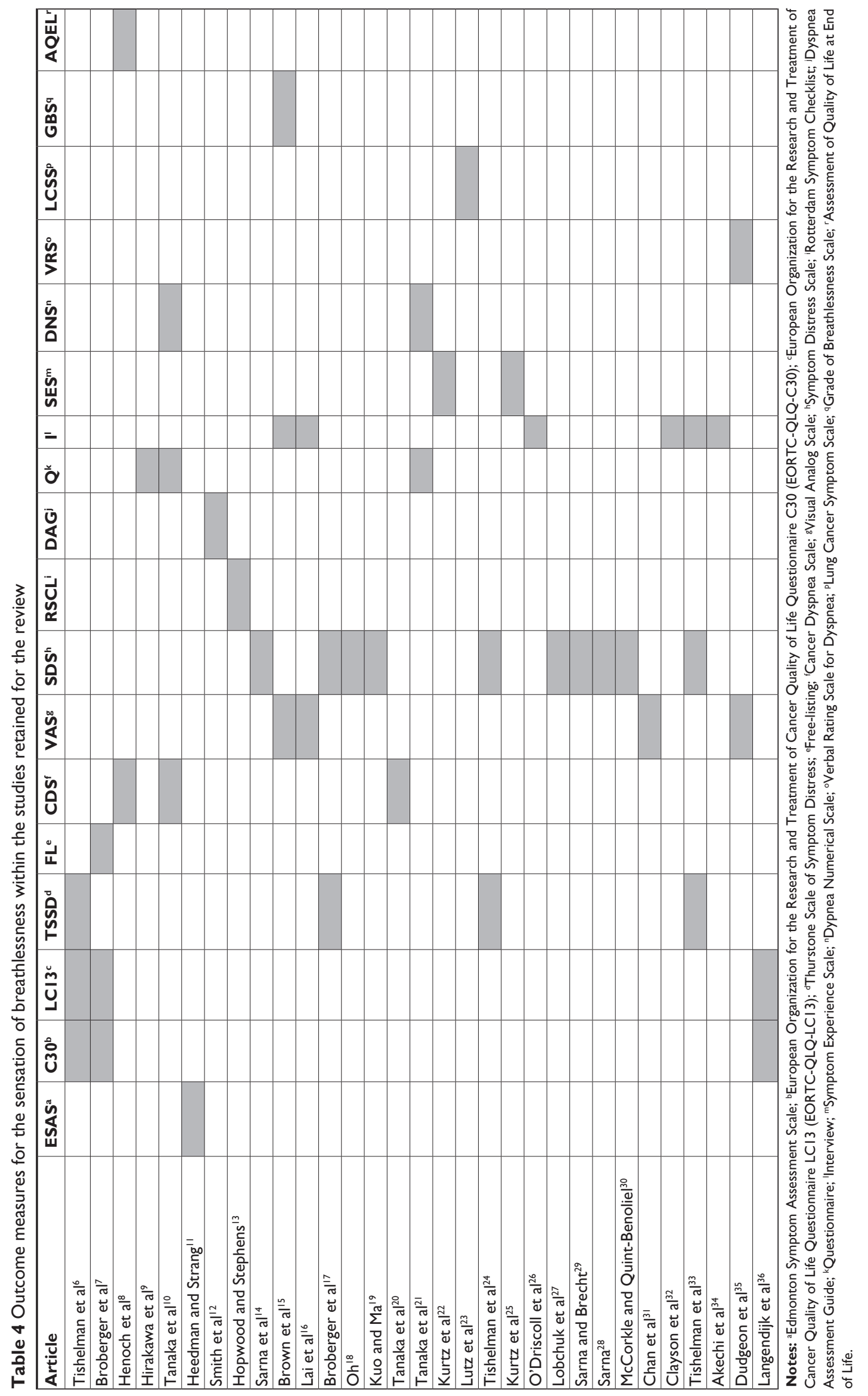


Table 5 Outcome measures categorized according to the mode of dyspnea assessment

\begin{tabular}{|c|c|}
\hline Domain & Outcome measure \\
\hline Symptom intensity & $\begin{array}{l}\text { Visual Analog Scale (VAS), Edmonton } \\
\text { Symptom Assessment Scale (ESAS), } \\
\text { Dyspnea Numerical Scale (DNS), Grade } \\
\text { of Breathlessness Scale (GBS), European } \\
\text { Organization for the Research and Treatment } \\
\text { of Cancer Quality of Life Questionnaires } \\
\text { (EORTC-QLQ-C30 and EORTC-QLQ-LCI3), } \\
\text { Assessment of Quality of Life at the End of Life } \\
\text { questionnaire (AQEL) }\end{array}$ \\
\hline Quality of life & Questionnaires \\
\hline Symptom distress & $\begin{array}{l}\text { Thurstone Scale of Symptom Distress (TSSD), } \\
\text { Cancer Dyspnea Scale (CDS), Symptom } \\
\text { Distress Scale (SDS), Free-listing }\end{array}$ \\
\hline Symptom prevalence & $\begin{array}{l}\text { Lung Cancer Symptom Scale (LCSS), } \\
\text { Questionnaire, Symptom Experience Scale } \\
\text { (SES), Rotterdam Symptom Checklist (RSCL), } \\
\text { Verbal Rating Scale for Dyspnea (VRS), VAS, } \\
\text { Interview, Dyspnea Assessment Guide (DAG) }\end{array}$ \\
\hline Interview & Interview, Free-listing \\
\hline
\end{tabular}

studies indicate a moderate intensity of dyspnea; however, the individual VAS results for the four studies convey markedly varied reports of dyspnea intensity.

\section{Dyspnea numerical scale}

Using the Dyspnea Numerical Scale (DNS), Tanaka et al reported in two studies a median DNS score of 2 out of 10 (range 0-9). ${ }^{10,21}$ In one of these studies, the mean DNS score was reported to be 2.2 out of $10,{ }^{21}$ while in the other study, the mean score was not reported. ${ }^{10}$ Overall, this indicates a low intensity of dyspnea.

\section{Grade of breathlessness scale}

Using the Grade of Breathlessness Scale (GBS), Brown et al reported the mean dyspnea score to be 3.64 on a 0 (no shortness of breath) to 5 (too breathless to leave the house) scale (baseline measure). ${ }^{15}$ This indicates a moderatehigh intensity of dyspnea.

\section{European organization for the research and treatment of cancer quality of life questionnaire C30 and LCI3, assessment of quality of life at the end of life questionnaire}

The above three outcome measures assess quality of life via questionnaires; however, they have been included in the above section as the breathlessness components of the quality of life questionnaires by themselves do not convey quality of life. The average dyspnea score for the three studies, assessed using the European Organization for the Research and Treatment of Cancer Quality of Life Questionnaire C30 (EORTC-QLQ-C30) and EORTC-QLQ-LC13 was 46 (0-100 scale), where a higher score indicates a greater degree of symptoms (and a likely poorer quality of life). These results signify a moderate degree of dyspnea (Table 6). Henoch et al used the Assessment of Quality of Life at the End of Life questionnaire (AQEL) to assess quality of life at end of life. ${ }^{8}$ Individual dyspnea scores were reported to be 8.5 (1-10 scale) (averaged over five time periods), whereby higher scores indicate less symptom burden. This study indicates a rather low dyspnea burden.

\section{Quality of life Questionnaires}

Tanaka et al, in two studies, used "interference" questionnaires to investigate the impact of dyspnea on activities of daily living. ${ }^{10,21}$ In one of those studies, the authors reported that $52 \%(\mathrm{n}=81)$ of a subject's dyspnea interfered with any physical domain, while $23 \%(\mathrm{n}=36)$ interfered with any psychological domain. In the other study, they reported that dyspnea interfered with at least one daily life activity in $55 \%$ of patients $(n=94) .^{21}$

Table 6 Individual dyspnea scores as assessed by the EORTC-QLQ-C30 and EORTC-QLQ-LCI3

\begin{tabular}{|c|c|c|c|c|}
\hline $\begin{array}{l}\text { Mean dyspnea score } \\
(0-100)\end{array}$ & Tishelman et $\mathrm{al}^{6}$ & 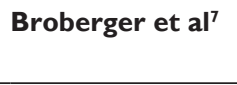 & Langendijk et $\mathrm{al}^{36}$ & Henoch et $\mathrm{al}^{8}$ \\
\hline EORTC-QLQ-C30 & $\begin{array}{l}53 \text { (average six } \\
\text { time periods) }\end{array}$ & $\begin{array}{l}63 \text { (average three } \\
\text { time periods) }\end{array}$ & $\begin{array}{l}38 \text { (average three groups, } \\
\mathrm{C} 30 \text { and } \mathrm{LCI} 3 \text { not } \\
\text { differentiated between) }\end{array}$ & \\
\hline EORTC-QLQ- LCI3 & $\begin{array}{l}39 \text { (average six } \\
\text { time periods) }\end{array}$ & $\begin{array}{l}39 \text { (average } 3 \text { time } \\
\text { periods) }\end{array}$ & & \\
\hline AQEL & & & & $\begin{array}{l}8.5 \text { (averaged over } \\
\text { five time periods }\end{array}$ \\
\hline
\end{tabular}

Abbreviations: AQEL, Assessment of Quality of Life at the End of Life questionnaire; EORTC-QLQ-C30/LCI3, European Organization for the Research and Treatment of Cancer Quality of Life Questionnaire C30/LCI3. 
Table 7 Individual Symptom Distress Scale (SDS) scores

\begin{tabular}{|c|c|}
\hline Article & SDS score \\
\hline Sarna et al $^{14}$ & 1.9 \\
\hline Broberger et $\mathrm{al}^{17}$ & $2.2^{\mathrm{a}}$ \\
\hline $\mathrm{Oh}^{18}$ & 2.48 \\
\hline Kuo and $\mathrm{Ma}^{19}$ & 0.81 \\
\hline Tishelman et $\mathrm{al}^{24}$ & $2.31^{\mathrm{b}}$ \\
\hline Lobchuk et $\mathrm{al}^{27}$ & 2.22 \\
\hline Sarna and Brecht ${ }^{29}$ & 1.80 \\
\hline Sarna $^{28}$ & $\mathrm{I} .78$ \\
\hline McCorkle and Quint-Benoliel ${ }^{30}$ & $\mathrm{I} .88^{\mathrm{b}}$ \\
\hline Tishelman et $\mathrm{al}^{33}$ & $3.6^{\mathrm{b}}$ \\
\hline
\end{tabular}

Notes: aAveraged over several time periods; 'Baseline measure.

\section{Symptom distress}

Thurstone scale of symptom distress

Interestingly, of the four studies assessing distress associated with dyspnea using the Thurstone Scale of Symptom Distress (TSSD), the majority report dyspnea to be ranked as the number one distress-causing symptom in lung cancer. Of the four studies, one by Tishelman et $\mathrm{al}^{6}$ (in all six time periods), one by Broberger et a $1^{17}$ (average over several time periods), and another by Tishelman et $\mathrm{al}^{33}$ (baseline) all reported dyspnea to have a TSSD ranking of 1 , while yet another by Tishelman et $\mathrm{al}^{24}$ (baseline) reported dyspnea to have a TSSD ranking of 2 .

\section{Cancer dyspnea scale}

Three studies used the multidimensional Cancer Dyspnea Scale (CDS) to assess dyspnea, with two reporting median values $^{10,20}$ and two reporting mean values. ${ }^{8,20}$ The combined average total dyspnea score was 7 (out of 48), with median 7 , indicating a less severe dyspnea experience. Henoch et $\mathrm{al}^{8}$ (baseline measure) reported a mean CDS score of 5.80, while Tanaka et $\mathrm{al}^{20}$ reported a mean score of 8 and median score of 7 . Similarly, Tanaka et al ${ }^{10}$ reported a median CDS score of 7.

\section{Symptom distress scale}

The 10 studies using the Symptom Distress Scale (SDS) to assess distress associated with dyspnea reveal a combined average score of 2.1 out of 5 (Table 7). This indicates a moderate level of distress associated with dyspnea overall.

\section{Free-listing}

Free-listing (FL) is a structured approach allowing identification of relevant issues without imposing researchers' assumptions and was used to ascertain the patient's most distressing symptoms. ${ }^{7}$ Patients most frequently reported fatigue, pain, and dyspnea as concerns causing them the most distress at both baseline and 6 months follow-up. ${ }^{7}$

\section{Symptom prevalence}

A variety of outcomes were used to report on the prevalence of dyspnea. Table 8 presents the percentage of subjects within each study reporting the presence of dyspnea. The average prevalence reported by studies included in this review was $70.5 \%$, with a range of $50 \%-87 \%$. This indicates a high prevalence of dyspnea (Table 8 ).

\section{Interview}

The studies that included interviews as an outcome measure assessed many different aspects of dyspnea. These included the physical and emotional sensations (language) of dyspnea, thoughts, feelings, and experiences of dyspnea, causes of dyspnea, the effect of dyspnea on the person's life, and their management of dyspnea. While it was not their primary purpose, six studies report on the language used to describe dyspnea. ${ }^{7,15,16,26,32,33}$ All six studies obtain dyspnea descriptors via interviews, using words volunteered by subjects and/or words selected from a pre-existing list of breathlessness descriptors. An article by Wilcock et al is the only study to date that has investigated the language of

Table 8 Dyspnea prevalence (all values in \% [n])

\begin{tabular}{|c|c|c|c|c|c|c|c|c|c|c|}
\hline \multirow{2}{*}{$\begin{array}{l}\text { Outcome } \\
\text { measure }\end{array}$} & \multicolumn{10}{|l|}{ Article } \\
\hline & $\begin{array}{l}\text { Lutz } \\
\text { et } \mathbf{~ a l}^{23}\end{array}$ & $\begin{array}{l}\text { Hirakawa } \\
\text { et al }{ }^{9}\end{array}$ & $\begin{array}{l}\text { Kurtz } \\
\text { et } \mathbf{a l}^{22}\end{array}$ & $\begin{array}{l}\text { Kurtz } \\
\text { et } \mathrm{al}^{25}\end{array}$ & $\begin{array}{l}\text { Chan } \\
\text { et } a^{3 !}\end{array}$ & $\begin{array}{l}\text { Dudgeon } \\
\text { et } \mathrm{al}^{35}\end{array}$ & $\begin{array}{l}\text { Clayson } \\
\text { et } \mathrm{al}^{32}\end{array}$ & $\begin{array}{l}\text { Akechi } \\
\text { et } \mathbf{a l}^{34}\end{array}$ & $\begin{array}{l}\text { Hopwood and } \\
\text { Stephens }{ }^{13}\end{array}$ & $\begin{array}{l}\text { Smith } \\
\text { et } \mathrm{al}^{12}\end{array}$ \\
\hline LCSS & $73(60)$ & & & & & & & & & \\
\hline Questionnaire & & $82(27)$ & & & & & & & & \\
\hline SES & & & $56(228)^{a}$ & $6 I(79)$ & & & & & & \\
\hline VAS and VRS & & & & & $59(27)^{a}$ & $84(37)$ & & & & \\
\hline Interview & & & & & & & $50(7)$ & $66(59)^{c}$ & & \\
\hline $\mathrm{RSCL}$ & & & & & & & & & 87 (819) & \\
\hline DAG & & & & & & & & & & $87(115)$ \\
\hline
\end{tabular}

Notes: 'Baseline measure; ${ }^{b}$ Estimated from graph; 'Averaged over several time periods.

Abbreviations: DAG, Dyspnea Assessment Guide; LCSS, Lung Cancer Symptom Scale; RSCL, Rotterdam Symptom Checklist; SES, Symptom Experience Scale; VAS, Visual Analog Scale; VRS, Verbal Rating Scale for dyspnea. 
Table 9 Most commonly reported dyspnea descriptors in the seven studies that included data on the language of breathlessness

\begin{tabular}{|c|c|}
\hline Article & Descriptor \\
\hline Brown et al ${ }^{15}$ & Short of breath ${ }^{\mathrm{a}}$ \\
\hline \multirow[t]{3}{*}{ (two time periods) } & Difficulty breathing ${ }^{a}$ \\
\hline & Hard to move air ${ }^{\mathrm{a}}$ \\
\hline & Tired or fatigued ${ }^{\mathrm{a}}$ \\
\hline \multirow[t]{4}{*}{ O'Driscoll et a ${ }^{26}$} & Shortness of breath ${ }^{\mathrm{a}}$ \\
\hline & Panic $^{\mathrm{a}}$ \\
\hline & Feeling of impending death \\
\hline & Fear/fright ${ }^{\mathrm{a}}$ \\
\hline \multirow[t]{2}{*}{ Clayson et $\mathrm{al}^{32}$} & Fighting for breath ${ }^{\mathrm{a}}$ \\
\hline & Gasping for air ${ }^{\mathrm{a}}$ \\
\hline \multirow[t]{5}{*}{ Lai et al ${ }^{16}$} & Labor $^{\mathrm{a}}$ \\
\hline & Suffocating ${ }^{\mathrm{a}}$ \\
\hline & Tight $^{\mathrm{a}}$ \\
\hline & Can't breathe ${ }^{a}$ \\
\hline & Awful ${ }^{\mathrm{a}}$ \\
\hline \multirow{3}{*}{$\begin{array}{l}\text { Broberger et } \mathrm{al}^{7} \\
\text { (two time periods) }\end{array}$} & Decreased breathing \\
\hline & capacity \\
\hline & Short of breath \\
\hline Tishelman et $\mathrm{al}^{33}$ & Frightening \\
\hline (several time periods) & Distress \\
\hline \multirow[t]{2}{*}{ Wilcock et $\mathrm{al}^{37}$} & I feel out of breath ${ }^{\mathrm{b}}$ \\
\hline & I cannot get enough airb \\
\hline
\end{tabular}

Notes: ${ }^{\text {V} V o l u n t e e r e d ~ d e s c r i p t o r s ; ~}{ }^{b}$ Endorsed descriptors.

breathlessness in lung cancer patients using the "endorsed" descriptor method. ${ }^{37}$ It should be noted that the article was not identified during the systematic search, nor did any of the studies included within the review refer to this study. The volunteered descriptors reported in the articles by Lai et a ${ }^{16}$ and Tishelman et $\mathrm{al},{ }^{33}$ reported below, are not verbatim from the articles, but instead have been classified into breathlessness categories by the review authors. All other studies using volunteered language have taken subjects' descriptors and grouped them into similar categories in order to report them (some also reporting the original descriptors as well). Table 9 highlights the most commonly reported dyspnea descriptors in the seven studies.

With the exception of the endorsed descriptors in Wilcock et al's study which do not have an affective component, four out of the six studies on language report both physical and affective terms to describe dyspnea. ${ }^{37}$ The physical descriptors conveying "shortness of breath", "difficulty breathing", and/or "labor" type words are common to most studies. With the exception of "frightening", the affective terms used to describe dyspnea differ between studies; however, all of the terms indicate considerable distress associated with the sensation of dyspnea. Inaccurate categorizing as well as generalization when reporting the data and differences in sample size and research design may account for differences between the terms used to describe dyspnea in the above studies.

\section{Degree of unpleasantness with dyspnea in people with all stages of lung cancer}

The studies included within this systematic review fall into two groups: those reporting on all stages of lung cancer (I-IV), or those only reporting on advanced-stage lung cancer (III, IV, or extensive disease). The studies were further analyzed to determine whether any relationship existed between the stage of lung cancer and the level of distress associated with dyspnea. Table 10 outlines the studies including subjects with all types of lung cancer, and the corresponding degree of dyspnea unpleasantness:

Table 10 Degree of unpleasantness with dyspnea in studies that include subjects with all stages of lung cancer

\begin{tabular}{|c|c|c|c|c|}
\hline Article & Data group & Outcome measure & Data & Degree of unpleasantness \\
\hline \multirow[t]{3}{*}{ Tishelman et $\mathrm{al}^{6}$} & \multirow[t]{3}{*}{ Intensity, Distress } & EORTC-QLQ-C30, & $\mathrm{C} 30=53$ & \multirow[t]{3}{*}{ Moderate } \\
\hline & & EORTC-QLQ-LCI3 and TSSD & $\mathrm{LCI} 3=39$ & \\
\hline & & & TSSD $=1$ & \\
\hline Smith et $\mathrm{al}^{12}$ & Prevalence & DAG & $87 \%(n=115)$ & High \\
\hline $\mathrm{Oh}^{18}$ & Distress & SDS & 2.48 & Moderate \\
\hline Kurtz et $\mathrm{a}^{22}$ & Prevalence & SES & $56 \%(n=228)$ & Moderate \\
\hline Kurtz et $\mathrm{al}^{25}$ & Prevalence & SES & $61 \%(\mathrm{n}=79)$ & High \\
\hline Lobchuk et al ${ }^{27}$ & Distress & SDS & 2.22 & Moderate \\
\hline \multirow[t]{3}{*}{ Tishelman et $\mathrm{al}^{33}$} & \multirow[t]{3}{*}{ Distress, Interview } & TSSD, SDS, volunteered & $\mathrm{TSSD}=\mathrm{I}$ & \multirow[t]{3}{*}{ High } \\
\hline & & language & $\mathrm{SDS}=3.6$ & \\
\hline & & & Frightening, distress & \\
\hline \multirow[t]{2}{*}{ Langendijk et $\mathrm{al}^{36}$} & \multirow[t]{2}{*}{ Intensity } & EORTC-QLQ-C30 & $\mathrm{C} 30+\mathrm{LCI} 3=38$ & \multirow[t]{2}{*}{ Moderate } \\
\hline & & and EORTC-QLQ-LCI3 & & \\
\hline
\end{tabular}

Abbreviations: DAG, Dyspnea Assessment Guide; EORTC-QLQ-C30/LCI3, European Organization for the Research and Treatment of Cancer Quality of Life Questionnaire C30/LCI3; SDS, Symptom Distress Scale; SES, Symptom Experience Scale; TSSD, Thurstone Scale of Symptom Distress. 
Table I I Degree of unpleasantness with dyspnea in studies that include subjects with late stage lung cancer

\begin{tabular}{|c|c|c|c|c|}
\hline Article & Data group & Outcome measure(s) & Data & Degree of unpleasantness \\
\hline \multirow[t]{3}{*}{ Tanaka et al ${ }^{10}$} & Intensity, Distress, & DNS, CDS, Q & DNS = 2 (median) & Low to moderate \\
\hline & Quality of Life & & $\mathrm{CDS}=7$ (median) & \\
\hline & & & $Q=52 \%(n=8 I)$ & \\
\hline \multirow[t]{6}{*}{ Brown et al ${ }^{15}$} & Intensity, Interview & VAS, GBS, & VAS $=39.54$ & Moderate \\
\hline & & volunteered language & $\mathrm{GBS}=3.64$ & \\
\hline & & & Short of breath & \\
\hline & & & Difficulty breathing & \\
\hline & & & Hard to move air & \\
\hline & & & Tired or fatigued & \\
\hline \multirow[t]{6}{*}{ Lai et al ${ }^{16}$} & Intensity, Interview & VAS, volunteered language & VAS $=73.3$ & High \\
\hline & & & Labor & \\
\hline & & & Suffocating & \\
\hline & & & Tight & \\
\hline & & & Can't breathe & \\
\hline & & & Awful & \\
\hline Kuo and $\mathrm{Ma}^{19}$ & Distress & SDS & 0.81 & Low \\
\hline Tanaka et $\mathrm{al}^{20}$ & Distress & CDS & 7 (median) & Low \\
\hline \multirow[t]{2}{*}{ Tanaka et $\mathrm{al}^{21}$} & Intensity, Quality of Life & DNS, Q & DNS = 2 (median) & Low to moderate \\
\hline & & & $Q=55 \%(n=94)$ & \\
\hline Lutz et $\mathrm{al}^{23}$ & Prevalence & LCSS & $73 \%(n=60)$ & High \\
\hline Sarna and Brecht ${ }^{29}$ & Distress & SDS & 1.8 & Low \\
\hline Chan et $\mathrm{a}^{31}$ & Intensity & VAS & 8.44 & Low \\
\hline Akechi et $\mathrm{al}^{34}$ & Prevalence & I & $66 \%(n=59)$ & High \\
\hline
\end{tabular}

Abbreviations: CDS, Cancer Dyspnea Scale; DNS, Dypnea Numerical Scale; GBS, Grade of Breathlessness Scale; I, interview; LCSS, Lung Cancer Symptom Scale; $\mathrm{Q}$, questionnaire; SDS, Symptom Distress Scale; VAS, Visual Analog Scale.

low, moderate, or high, as reported in previous sections. Table 11 outlines the studies including only subjects with late stage lung cancer, and the subsequent degree of dyspnea unpleasantness.

From Tables 10 and 11, it can be seen that the studies reporting on subjects with all stages of lung cancer generally had a moderate-high degree of unpleasantness associated with dyspnea. Conversely, the studies reporting on subjects with advanced lung cancer generally had a larger spread of unpleasantness, ranging from low to high. This suggests that there is no clear relationship between the stage of cancer and level of distress, contrary to the notion that the more advanced the lung cancer, the higher the distress associated with dyspnea becomes.

\section{Conclusion}

It is clear that a variety of different outcome measures was used to assess the experience of dyspnea and that varying results were obtained regarding the intensity, prevalence, and distress associated with dyspnea. Overall, the studies report a high prevalence of dyspnea in lung cancer patients, with subjects experiencing a moderate level of dyspnea intensity and interference with activities of daily living. Distress associated with breathing appears to be variable, with some studies reporting dyspnea to be the most distressing sensation, while others report lower levels of distress. The language used to describe the qualitative sensation of dyspnea involves both physical and affective words. Physical descriptors conveying "shortness of breath", "difficulty breathing", and/or "labor" type words were common to all studies; however, with the exception of "frightening", the affective terms used to describe dyspnea differ between studies, although all of the affective terms used indicate considerable distress associated with the sensation of dyspnea. However, taking into account the prevalence, intensity, and distress of dyspnea, the general consensus appears to be that the experience of dyspnea in people with lung cancer is common, with varying degrees of intensity, but involves considerable unpleasantness. Thus, if dyspnea is a distressing sensation for people with lung cancer, this has potential implications for both clinical and academic areas with regards to both management strategies and further research.

\section{Disclosure}

The authors declare that they do not have any financial relationship/interest in a commercial organization that could pose a conflict of interest. 


\section{References}

1. World Health Organization (WHO). Cancer. 2006 Feb. Available from: http://www.who.int/mediacentre/factsheets/fs297/en/. Accessed 2007 Jun 25.

2. American Cancer Society. Cancer statistics 2008: a presentation from the American Cancer Society [cited 2008 Sep 30]. Available from: http:// www.cancer.org/downloads/STT/Cancer_Statistics_2008.ppt. Accessed 2007 Jun 25

3. Beckles MA, Spiro SG, Colice GL, Rudd RM. Initial evaluation of the patient with lung cancer: symptoms, signs, laboratory tests and paraneoplastic syndromes. Chest. 2003;123 Suppl 1:97S-104S.

4. Banzett RB, Moosavi SH. Dyspnea and pain: similarities and contrasts between two very unpleasant sensations. APS Bulletin. 2001;11(1):1-6.

5. Higgins JPT, Green S, editors. Cochrane Handbook for Systematic Reviews of Interventions, Version 5.0.0 [updated 2008 Feb; cited 2008 Jul 14]. The Cochrane Collaboration. Available from: www. cochrane-handbook.org. Accessed 2010 Oct 17.

6. Tishelman C, Petersson L, Degner LF, Sprangers MAG. Symptom prevalence, intensity, and distress in patients with inoperable lung cancer in relation to time of death. J Clin Oncol. 2007;25(34):5381-5389.

7. Broberger E, Tishelman C, von Essen L, Doukkali E, Sprangers MAG. Spontaneous reports of most distressing concerns in patients with inoperable lung cancer: at present, in retrospect and in comparison with EORTC-QLQ-C30+LC13. Qual Life Res. 2007;16:1635-1645.

8. Henoch I, Bergman B, Gustafsson M, Gaston-Johansson F, Danielson E. The impact of symptoms, coping capacity, and social support on quality of life experience over time in patients with lung cancer. J Pain Symptom Manage. 2007;34(4):370-379.

9. Hirakawa Y, Masuda Y, Kuzuya M, Iguchi A, Uemura, K. Symptoms and care of elderly patients dying at home of lung, gastric, colon, and liver cancer. Japan Medical Association Journal. 2006;49(4):140-145.

10. Tanaka K, Akechi T, Okuyama T, Nishiwaki Y, Uchitomi Y. Prevalence and screening of dyspnea interfering with daily life activities in ambulatory patients with advanced lung cancer. J Pain Symptom Manage. 2002;23(6):484-488.

11. Heedman PA, Strang P. Symptom assessment in advanced palliative home care for cancer patients using the ESAS: clinical aspects. Anticancer Res. 2001;21:4077-4082.

12. Smith EL, Hann DM, Ahles TA, et al. Dyspnea, anxiety, body consciousness, and quality of life in patients with lung cancer. J Pain Symptom Manage. 2001;21(4):323-329.

13. Hopwood P, Stephens RJ. Symptoms at presentation for treatment in patients with lung cancer: implications for the evaluation of palliative treatment. Br J Cancer. 1995;7:633-636.

14. Sarna L. Correlates of symptom distress in women with lung cancer. Cancer Pract. 1993;1(1):21-28.

15. Brown ML, Carrieri V, Jansen-Bjerklie S, Dodd MJ. Lung cancer and dyspnea: the patient's perception. Oncol Nurs Forum. 1986;13(5):19-24.

16. Lai YL, Carmen WH, Lopez V. Perceptions of dyspnea and helpful interventions during the advanced stage of lung cancer: Chinese patient's perspectives. Cancer Nurs. 2007;30(2):1-8.

17. Broberger E, Tishelman C, von Essen L. Discrepancies and similarities in how patients with lung cancer and their professional and family caregivers assess symptom occurrence and symptom distress. J Pain Symptom Manage. 2005;29(6):572-582.

18. Oh E. Symptom experience in Korean adults with lung cancer. J Pain Symptom Manage. 2004;28(2):133-139.

Lung Cancer: Targets and Therapy

\section{Publish your work in this journal}

Lung Cancer: Targets and Therapy is an international, peer-reviewed, open access journal focusing on lung cancer research, identification of therapeutic targets and the optimal use of preventative and integrated treatment interventions to achieve improved outcomes, enhanced survival and quality of life for the cancer patient. Specific topics covered in the journal include:
19. Kuo T, Ma, F. Symptom distresses and coping strategies in patients with non-small cell lung cancer. Cancer Nurs. 2002;25(4):309-317.

20. Tanaka K, Akechi T, Okuyama T, Nishiwaki Y, Uchitomi Y. Factors correlated with dyspnea in advanced lung cancer patients: organic causes and what else? J Pain Symptom Manage. 2002;23(6):490-500.

21. Tanaka K, Akechi T, Okuyama T, Nishiwaki Y, Uchitomi Y. Impact of dyspnea, pain and fatigue on daily life activities in ambulatory patients with advanced cancer. J Pain Symptom Manage. 2002;23(5):417-423.

22. Kurtz ME, Kurtz JC, Stommel M, Given CW, Given BA. Predictors of depressive symptomatology of geriatric patients with lung cancer - a longitudinal analysis. Psycho-Oncology. 2002;11:12-22.

23. Lutz S, Norrell R, Bertucio C, et al. Symptom frequency and severity in patients with metastatic or locally recurrent lung cancer: a prospective study using the Lung Cancer Symptom Scale in a community hospital. $J$ Palliat Med. 2001;4(2):157-165.

24. Tishelman C, Degner L, Mueller B. Measuring symptom distress in patients with lung cancer: a pilot study of experienced intensity and importance of symptoms. Cancer Nurs. 2000;23(2):82-90.

25. Kurtz ME, Kurtz JC, Stommel M, Given CW, Given BA. Symptomatology and loss of physical functioning among geriatric patients with lung cancer. J Pain Symptom Manage. 2000;19(4):249-256.

26. O'Driscoll M, Corner J, Bailey C. The experience of breathlessness in lung cancer. Eur J Cancer Care. 1999;8:37-43.

27. Lobchuk MM, Kristjanson L, Degner L, Blood P, Sloan JA. Perceptions of symptom distress in lung cancer patients: I. Congruence between patients and primary family caregivers. J Pain Symptom Manage. 1997;14(3):136-146.

28. Sarna L. Smoking behaviors of women after diagnosis with lung cancer. Image J Nurs Sch. 1995;27(1):35-41.

29. Sarna L, Brecht M. Dimensions of symptom distress in women with advanced lung cancer: a factor analysis. Heart Lung. 1997;26(1): 23-30.

30. McCorkle R, Quint-Benoliel J. Symptom distress, current concerns and mood disturbance after diagnosis of life-threatening disease. Soc Sci Med. 1983;17(7):431-438.

31. Chan CWH, Richardson A, Richardson J. A study to assess the existence of the symptom cluster of breathlessness, fatigue and anxiety in patients with advanced lung cancer. Eur J Oncol Nurs. 2005;9:325-333.

32. Clayson H, Seymour J, Noble B. Mesothelioma from the patient's perspective. Hematol Oncol Clin North Am. 2005;19:1175-1190.

33. Tishelman C, Degner LF, Rudman A, et al. Symptoms in patients with lung carcinoma: distinguishing distress from intensity. Cancer. 2005;104(9):2013-2021.

34. Akechi T, Okamura H, Nishiwaki Y, Uchitomi Y. Predictive factors for suicidal ideation in patients with unresectable lung carcinoma: a 6-month follow-up study. Cancer. 2002;95(5):1085-1093.

35. Dudgeon DJ, Kristjanson L, Sloan JA, Lertzmann M, Clement K. Dyspnea in cancer patients: prevalence and associated factors. J Pain Symptom Manage. 2001;21(2):95-101.

36. Langendijk JA, Aaronson NK, ten Velde GP, de Jong JM, Mueller MJ, Wouters EF. Pretreatment quality of life of inoperable non-small cell lung cancer patients referred for primary radiotherapy. Acta Oncol. 2000;39(8):949-958.

37. Wilcock A, Crosby V, Hughes A, Fielding K, Corcoran R, Tattersfield AE. Descriptors of breathlessness in patients with cancer and other cardiorespiratory diseases. J Pain Symptom Manage. 2002;23(3):182-189.

Epidemiology, detection and screening; Cellular research and biomarkers; Identification of biotargets and agents with novel mechanisms of action; Optimal clinical use of existing anticancer agents, including combination therapies; Radiation and surgery; Palliative care; Patient adherence, quality of life, satisfaction; Health economic evaluations. 